Apresentação do dossiê

\title{
Histórico, relevância e explorações ontológicas da questão ambiental
}

\section{Resumo}

De forma breve, é traçado um panorama histórico e discutidas as explorações ontológicas e abordagens teóricas da "questão ambiental" nas Ciências Sociais, situando as principais correntes, temas e possibilidades investigativas que fundamentam o ambiente como um todo, como entidade em si. Buscando estabelecer relações com essa trajetória da questão ambiental, o texto também apresenta os artigos que integram este dossiê. Estes visam garantir a diversidade teórico-metodológica de pesquisas sociais no tema ambiental e abarcar a maior variedade de abordagens, com um diapasão que busca intercalar teoria e empírico acerca de questões que tratam dos problemas ambientais vivenciados pelas sociedades contemporâneas.

Palavras-chave: Sociologia ambiental. Ciências Sociais e ambiente. Ontologia natureza/sociedade.

\footnotetext{
* Universidade Federal do Rio Grande do Sul (UFRGS), Porto Alegre, Rio Grande do Sul, Brasil.

${ }^{* *}$ Fundação Amazônica de Defesa da Biosfera (FDB), Manaus, Amazonas, Brasil.
} 


\section{History, relevance and ontological explorations of the environmental issues}

A brief historical overview of the "environmental issue" is outlined here, while exploring Social Sciences ontological and theoretical approaches to this issue. The main trends, themes and research possibilities that underlie the environment as a whole are discussed. Seeking to establish the relationships involved in the development of the environmental issue, the text also presents the articles that compose this dossier. This latter aims to comprise the theoretical and methodological diversity of social research on environmental issues and cover a broad range of perspectives, by combining theoretical and empirical approaches on issues related to the environmental problems manifested in contemporary societies.

Keywords: Environmental sociology. Social sciences and environment. Nature/society ontology.

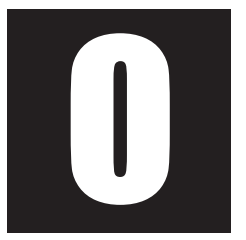

constante debate sobre o ambiente ${ }^{1}$ (ou sobre a relação sociedade - natureza), os riscos e impactos negativos decorrentes da ação humana e as respostas ecossistêmicas, por meio das acomodações de fenômenos naturais que terminam por provocar riscos e desastres (poluição atmosférica, hídrica e de solos, desertificação e cheias, por exemplo) e comprometimento de modos de vida no futuro (mudanças climáticas), tornam o tema ambiental de interesse fundamental para as ciências sociais.

\footnotetext{
${ }^{1}$ Ambiente é aqui entendido como o conjunto de meios naturais ou artificializados da ecosfera onde o ser humano se instalou, que ele explora e administra, e o conjunto dos meios não antropizados necessários à sua sobrevivência. Estes meios são caracterizados por sua geometria, seus componentes físicos, químicos, biológicos e humanos e a distribuição espacial destes componentes; pelos processos de transformação, de ação ou de interação implicando estes componentes, fazendo-os mudar no espaço e no tempo; e por suas múltiplas dependências em relação às ações humanas (Jollivet; Pavé, 1993 apud Almeida, 2000, p. 5).
} 
Esse debate, historicamente, adentrou as ciências sociais de forma tangencial, como objeto de pesquisa orientado por correntes consolidadas da teoria social, dirigidas para entender, mais que o ambiente enquanto produção social, aspectos gerais das teorias sociais, como regimes de ação, dualidades estruturais do mundo social, organização e configuração de campos de poder. Ou seja, o ambiente era (ou é ainda) uma realidade social investigada como qualquer outra, tal como trabalho, saúde, corpo, cidade, consumo, religião e educação. Mas já existem abordagens, como se poderá verificar no artigo que abre este dossiê, em que a questão ambiental pressiona mudanças epistemológicas e teóricas de fundo nas ciências sociais. Isso leva à criação de programas de pesquisa críticos às metas clássicas das ciências sociais na compreensão e descrição de ações humanas discricionárias em relação aos fatores ambientais ou ecológicos que impõem condições limite, justamente, a estas ações. Ao cabo, as discussões atingem o além-fronteiras de diversas disciplinas, lançando-se às possibilidades e variações ontológicas que o atrito sociedade/natureza cria nas formulações teóricas contemporâneas.

Se natureza, ambiente e sociedade são noções de chegada da mobilização de mundos e da estabilização de ideias e conceitos, as perspectivas realistas de mundo são postas em xeque, não obstante o caráter pungente da condição humana estar apegado a alguma noção de ambiente ou natureza. Isso fornece, de um lado, a existência, a duração e as possibilidades da humanidade. Por outro lado, a humanidade, na sistemática heideggeriana (Foltz, 1995), é uma construtora de mundos, organizadora de experiências de percepção e imaginário e de categorias denotativas da realidade. As abordagens do tema ambiental vão pendular entre estes polos, e incidirão, ao fim, nas discussões sobre modelos de sociedade e na ética da finitude que atravessa as argumentações sobre sustentabilidade e ecologia. 
Atualmente, as questões ambientais são pautas políticas de grande visibilidade, gerando contextos e situações em que diversos grupos sociais manifestam, por meio de exigências físicas (desastres ambientais) ou de direito (conselhos consultivos sobre a legitimidade de algum empreendimento, gestão de Unidades de Conservação, proteção de espécies ameaçadas, por exemplo), princípios que orientam suas ações e modos de vida. É certo que a exposição destas opiniões e posicionamentos gera disputas engendradas sob um quadro de poder mais ou menos estabilizado. Mas as ações podem tomar rumos inesperados, redirecionando os modos de governo dos registros argumentativos e das representações de mundo em jogo em dada formação social. As disputas em torno do ambiente, dos impactos sobre ele, explicitam a qualificação dos mundos e dos princípios em jogo nos regimes de ação (Boltanski; Thévenot, 2006), das trocas argumentativas, dos engajamentos e do sentido de justiça estabelecido pelas partes envolvidas na questão ambiental. O ambiente, assim, torna-se foco de atração/objeção de alianças e disputas, em constante elaboração pelos atores sociais. Acompanhar as justificativas de determinadas posições, compreender a gramática dos argumentos e os modelos de compromissos que se fazem entre as partes, está colocando o ambiente, como objeto empírico e teórico, cada vez mais como um dos grandes temas das ciências sociais.

A situação-problema imposta pelos impactos ambientais atinge tamanha complexidade e extensão, que mobiliza esforços globais para soluções. O ritmo em que as alterações ambientais se desenvolvem reclama repensar modelos e regimes de ação social, já que a gestão da produção de bens industriais e agrícolas, e a própria noção de bem-estar (como exigência política relativamente concreta em algumas formações sociais e países), são questionadas. A "questão ambiental", deste ponto de vista, também acaba englobando outros tipos de problema (além do desequilíbrio ecológico), já que pode resultar em crises econômicas, políticas, 
desigualdades e desestabilização sociais, representadas por fome, guerras e migrações forçadas.

A elaboração de conhecimento sobre as normas de interiorização da divisão natureza/sociedade, em como o ambiente é socialmente construído ou resultado de um processo social, como visões distintas se contrapõem e se tocam via pontos de consensos - na pluralidade de mundos (de uma perspectiva antropológica) - como é dimensionado pelo direito - como território - e como emerge como ente de reivindicações, por exemplo, é papel que as ciências sociais e humanas precisam assumir. Neste compasso, é necessário unir esforços com as ciências naturais e engenharias para elaborar respostas e soluções ousadas para os formuladores de políticas públicas e, mesmo, para pensar novos modelos políticos de convívio com as entidades e atores que constituem o mundo comum.

No contexto de degradação de solos, desmatamento, expansão da ocupação humana em áreas preservadas e mudanças climáticas, as representações mais fortes do ambiente são produzidas como artefatos científicos: mapas, imagens produzidas com auxílio de softwares, sistemas de posicionamento global, técnicas e equipamentos de sensoriamento remoto, computadores, satélites e outras tecnologias. O papel das ciências e dos cientistas é destacado ao criarem-se cenários ambientais a partir dessas ferramentas laboratoriais e dados colhidos em campo. Embora os estudos sociais da ciência e tecnologia já analisem as formas de produção desses conhecimentos, sobre como se ligam aos projetos maiores de conservação e como são apagadas algumas das condições de criação dessas representações - no fechamento das caixas-pretas -, os estudos ambientais, justamente pelo cruzamento de variadas teorias, problemas, métodos, hipóteses e financiamentos, instigam - ou mesmo confrontam - os cientistas sociais a pensar questões complexas impostas pelos desafios ambientais, como problema interdisciplinar e intersetorial. Isso pode alterar, sobremaneira, a própria estrutura institucional e as normas tácitas 
que têm mantido as ciências sociais, relativamente, em papel secundário nas pesquisas sobre ambiente e sustentabilidade.

As questões ambientais ligadas às perspectivas de escolhas de modelos tecnológicos na área de energia, transporte e sistemas de produção e consumo em geral, adquirem importância constantemente, pois tais estruturas materiais tendem a reproduzir padrões hegemônicos de desigualdades, acentuando, muitas vezes, a distribuição assimétrica dos seus impactos negativos. Abordagens teóricas ousadas são necessárias para entender a produção dos binários relacionados à divisão sociedade/natureza e buscar novos caminhos de análise. Diversas controvérsias sociotécnicas vinculadas ao ambiente ainda estão em aberto e perduram, seguindo uma trajetória de densificação de modelos produtivos polêmicos, como os ligados aos organismos geneticamente modificados (OGMs) e a alguns setores das nanotecnologias, que demandam novos ordenamentos para a gestão e regulação de seu uso.

As opções políticas para cenários futuros da sociedade estão ligadas intimamente a questões contextuais que surgem não apenas da curiosidade científica, mas de demandas sociais explícitas, decorrentes de problemas palpáveis, como acoplamentos entre cidades e entornos, regimes climáticos, ciclos de seca ou enchentes, integração entre paisagem natural e a criada pela ação humana, sistemas de energia de baixo carbono, relação e velocidade dos processos bióticos afetados por aspectos socioeconômicos dos modelos tecnológicos, sistemas produtivos mais sustentáveis, segurança alimentar e impactos da logística em escala global, por exemplo, áreas de pesquisa que as ciências sociais não podem abrir mão. Disso dependerá esforço interno em termos teóricos e metodológicos, ligados aos fenômenos socioambientais de estruturas de interação variável, a novas formas de conceber a integração de descrições quantitativas e qualitativas, à conciliação de métodos e princípios observacionais, como uso 
de conceitos, construção e interpretação de imagens, dados de satélite e outros equipamentos, estatísticas, entrevistas, questionários etc.

Parte do arrojo dos estudos sociais na área ambiental dependerá, também, de conseguir trabalhar com pesquisas em grandes escalas, com vultosos volumes de dados, com integração e gestão de bancos de dados de diversas áreas, interação entre pesquisa de campo e modelagem e simulação computacional, interfaces multiescalares entre biosfera-atmosfera, sistemas terrestres e aquáticos e as dimensões sociais das mudanças ambientais. No fundo, a perspectiva que se abre é encarar a vida não apenas como processos físico-químico-biológicos, mas também como um processo social. Além da aptidão para buscar financiamentos com regimes organizacionais e contratos orçamentários mais complexos, é necessária a abertura e construção de vocabulários e diálogos com outras áreas do conhecimento. Isso é uma etapa importante para, a partir da formação de um conjunto robusto de teorias, técnicas e métodos de pesquisa (além dos dados), as ciências sociais proporcionarem embasamento técnicocientífico para apoiar políticas públicas em diversos níveis de governo.

Além dessas questões, as quais trazem a reboque, no limite, discussões sobre ontologias variáveis, convertendo em sujeito (clima, parques naturais, animais de laboratório e OGMs, por exemplo) o que antes era objeto, dependendo das culturas envolvidas e dos processos e códigos de interpretação da realidade (Viveiros de Castro, 2002), abre-se a perspectiva para outras possibilidades de investigação. Em áreas rurais e urbanas o entrelaçamento e aglomeração de humanos e animais (domesticados e selvagens) ao longo da história, sempre geraram políticas de contato e interação entre espécies. A gestão de espaços tidos como naturais, pressionados antropicamente, aponta uma série de tendências de gestão de áreas específicas com este convívio interespécies, como em laboratórios e biotérios, por exemplo, e o ambiente mais amplo, como em Unidades de Conservação, com tecnologias de controle e sistemas regulatórios condicionados por estruturas de especialistas em bem-estar animal, dinâmica ecológica e 
sistemas de produção. As articulações que emergem destes aglomerados ou coletivos, cujas dinâmicas abarcam elementos não humanos, geram interesses das ciências sociais em novas perspectivas teóricas e metodológicas para abarcar modos de compreender as interações nos espaços de contato entre espécies diferentes e as formas de percepção e atuação de políticas que resultam em visões específicas de natureza e sociedade.

A divisão ontológica entre sociedade e mundo natural ou, na perspectiva deste dossiê, ambiente, é marcada nas ciências sociais por abordagens epistemológicas que ora transitam por modelos essencialistas (ou realistas) de divisão da realidade, ora por posições mais construtivistas. Estas tendem a ter primazia nas abordagens atuais, em que os argumentos sobre as questões ambientais são dispostos e contraditados de acordo com bases fincadas menos em verdades inquestionáveis, e mais na construção da credibilidade dos argumentos e dos pacotes interpretativos sob o peso de uma agenda que orienta o debate e estabelece o que é (e quem é) legítimo para se discutir. É claro que dados empíricos, em meio às pautas de discussão, são arrolados no acúmulo de dados para se firmar argumentos, mas o importante é seguir e compreender a configuração da agenda do debate em que o ambiente, como elemento significante de controvérsias e escolhas e, consequentemente, por meio da noção espeIho, a sociedade, são postos em questão.

O ambiente, enquanto agenda e objeto relativamente recente de pesquisas com enfoque social, atrai em torno de si um conjunto de conteúdos e valores geralmente indissociáveis da pauta tecnológica e científica ${ }^{2}$. A expansão e os impactos de empreendimentos baseados em conhecimen-

\footnotetext{
${ }^{2} \mathrm{O}$ tema "ambiente" surge efetivamente nas ciências sociais na década de 1970, como se verá um pouco mais adiante, com uma forte diversificação nas duas décadas seguintes, tanto do ponto de vista teórico como geográfico (Alonso; Costa, 2002). No caso brasileiro, é em meados da década de 1980 que se inicia a institucionalização do campo de conhecimento que trata da relação entre sociedade e natureza, com as primeiras iniciativas nas universidades de Campinas, São Paulo e Santa Catarina (Ferreira, 2006; Bacchiegga, 2013).
} 
to científico e tecnológico redundam na criação de uma região discursiva controversa, caracterizada pela diversidade e seleção de opiniões, em que o ambiente se fecha como realidade a partir das táticas de chegada na arregimentação de aliados, no caráter de urgência pública, na criação de interesse, na mobilização de teorias, nos dados, nas máquinas para corroborar uma posição, na elaboração de uma hierarquização de prioridades segundo trâmites determinados por compromissos políticos e econômicos.

Nas últimas três décadas, o ambiente se tornou um importante componente do debate social, assumindo uma dimensão polissêmica por excelência, permitindo todos os tipos de amálgamas, incorporando uma riqueza simbólica e uma real capacidade para provocar a mobilização social em torno das transferências de sentido que pode suscitar. No entanto, é difícil dizer, até agora, que lugar o mesmo ocupará neste debate. Do ponto de vista sociológico, pode-se falar de uma verdadeira ideologia, no sentido literal do termo, isto é, de um campo estruturado de representações sociais fundado sobre um sistema de valores sociais.

A amplitude das questões apresentadas em torno do tema caracteriza um profundo movimento social, isto é, um componente novo e duradouro da realidade social, do funcionamento e da evolução da sociedade. Neste contexto, o tema aparece para as ciências sociais como relevante e cada vez mais atualizado. Os trabalhos acadêmicos em torno da problemática (questão) ambiental que se pretendem no campo das ciências sociais, de forma geral, não são recentes. Eles são produtos de um amálgama de áreas e subdisciplinas já sedimentadas há décadas, tais como a Ecologia Humana, que surgiu estudando a mudança urbano/rural, os processos internos da cidade industrial, seus fatores dinâmicos e limitadores, as atitudes e valores do urbanismo; um ramo da Sociologia (dita) Rural, embasada na geografia e na antropologia econômicas, estudando comunidades diretamente dependentes de "recursos" naturais; e, a So- 
ciologia dos Recursos Naturais, estudando a gestão do ambiente, este entendido como "recurso natural", englobando desde estudos sobre política de terras públicas, planejamento de usos da terra, gestão das unidades de conservação etc.

Se poderia ainda acrescentar a contribuição de outras áreas e subdisciplinas à questão ambiental, como a Psicologia Social e a Antropologia Cultural, com estudos sobre atitudes e valores; a Sociologia dos Movimentos Sociais, enfocando novos sujeitos coletivos, suas agendas de lutas e conflitos; a Sociologia do Desenvolvimento, especialmente na sua vertente marxista, questionadora do mito do desenvolvimento; a Sociologia Urbana, tratando do ambiente construído; e os Estudos Sociais das Ciências e Tecnologias, analisando como o ambiente é socialmente construído, em parte, pelas ciências e tecnologias e o impacto destas quando sedimentadas e operadas socialmente por meio de artefatos e processos. ${ }^{3} \mathrm{~A}$ especificidade de uma ciência social voltada para o ambiente reside na retradução da problemática ambiental, tentando uma forma integradora do que até então (meados da década de 1950) era definido separadamente no quadro conceitual de cada uma destas áreas e subdisciplinas, e mesmo em outras áreas de conhecimento e atuação. Assim, por exemplo, o saneamento passou a ser visto como uma dimensão ambiental (assim como de saúde coletiva) e não apenas um tema dentro da questão urbana, de engenharia ou de medicina sanitária. Hoje, inclusive, fala-se muito em Saúde Ambiental.

É a partir da década de 1970, no entanto, que o que passa a ser convencionado como "Sociologia Ambiental" (SA) por alguns teóricos e pesquisadores acadêmicos aparece como pretensa subdisciplina acadêmica específica, refletindo sobre o ambientalismo (e o movimento ecologista), seus movimentos, valores e repercussão no mundo. Nos EUA, segundo

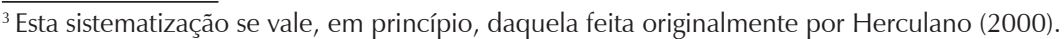


Dunlap e Catton (1978), expoentes acadêmicos da vertente realista da SA, esta sociologia surge como uma reflexão sobre o despontar da percepção de problemas ambientais (percepção que ficaria manifestada no Dia da Terra, em 1970; no relatório Meadows, em 1972; na Conferência da ONU, em Estocolmo, em 1972; nos movimentos ambientalistas e ecologistas etc.).

Após um declínio no início da década de 1980, devido a mudanças políticas internas nos EUA, a SA norte-americana e mundial se revitalizou, na medida em que a percepção dos problemas ambientais se aprofundou: em lugar da degradação ambiental ser percebida como um problema estético, esta passou a ser vista como ameaça à saúde e ao bem-estar e como risco tecnológico (por exemplo, o lixo tóxico em Love Canal, os acidentes nucleares de Three Mile Island, de Bhopal e de Chernobyl, a descoberta da destruição progressiva da camada de ozônio).

Nos anos 1990, os problemas em torno do ambiente passaram a constituir uma verdadeira "questão ambiental", na medida em que ganham maior dimensão, complexificam-se e adquirem uma institucionalidade global (por exemplo, por meio da criação, em 1992, da Comissão para o Desenvolvimento Sustentável e o Fundo Geral para o Meio Ambiente, ambos da ONU).

No âmbito sociológico acadêmico, a Associação Internacional de Sociologia (ISA) funda, em 1990, um novo comitê de pesquisa, o RC 24 - Meio Ambiente e Sociedade, com pesquisadores egressos das áreas da Ecologia Humana, das Sociologias Urbana e Rural, entre outros. No Brasil, a Associação Nacional de Pesquisa e Pós-Graduação em Ciências Sociais (ANPOCS) cria grupos de trabalho e mesas redondas direcionadas às pesquisas em que o tema ambiental é central (além da Associação Nacional de Pesquisa e Pós-Graduação em Ambiente e Sociedade - ANPPAS); além disso, diversos programas de pós-graduação passam a se dedicar à temática ambiental, alguns deles com uma ambição multi, inter e até mesmo transdisciplinar. 
O que passa gradativamente a se conformar como Sociologia Ambiental, com forte influência americana, no início, e depois ganhando força também na Europa - relembra Herculano (2000) - nasce com o que Buttel (1996) chama de partisan flavor, ou seja, com um toque parcial, proselitista, pois era (e ainda é) exercida muitas vezes por cientistas sociais militantes da causa ambientalista ou ecologista, trabalhando no sentido de construir argumentações para os movimentos sociais.

Mas por que o ambiente se transformou em uma verdadeira questão? Porque ele se configura como uma interrogação institucionalizada que mobiliza e organiza as representações sociais. A criação de ministérios públicos voltados ao ambiente consagra a "questão do meio ambiente" como tema inserido no espaço público. Algumas evidências podem ser apresentadas de imediato: o ambiente como trunfo político, entrando no jogo institucional da democracia regido pelo voto e pelos partidos; o lobby ecologista; e a construção de uma opinião pública cada vez mais sensibilizada pelos problemas ambientais (exploração de situações locais e em nível regional de conflitos para mostrar a legitimidade das posições ecologistas) (Almeida, 2000).

Fala-se frequentemente sobre a ética das relações sociais e do bemcomum. Esta parece ser uma ideologia verdadeiramente política, atualizando a questão democrática através de pontos essenciais, como o direito do cidadão à informação e à participação nas decisões de caráter público. Tudo isso é suficiente para tornar a análise da questão ambiental muito difícil, tarefa por vezes incômoda. Ainda mais porque esta é uma questão recente (sobretudo no Brasil), ainda em estado instável, não solidificado, portanto, aberto e permeável.

O ambiente como noção eivada de ideologias é fonte importante de equívocos e contradições, prestando-se, inclusive, ao jogo político, da esquerda à direita, de um simples economicismo à ecologia radical. 
Outra dimensão, a econômica (como mencionada no artigo de José Manuel Rodríguez Victoriano e Marina Requena i Mora, que integra este dossiê), também é bastante forte no debate e na análise da problemática ambiental. Esta trata da questão como um novo impulso para a economia industrial, por vezes aparecendo como apelo de marketing. Outra perspectiva é aquela que vê o ambiente como parte dos caminhos de acesso à "sociedade de serviços", à terceirização da economia (turismo verde, por exemplo), contribuindo, assim, para uma terceira fase do desenvolvimento que é aquela que privilegia os "mercados de clientela".

Uma terceira dimensão também se evidencia: a naturalista, ou seja, aquela que vê os problemas reais e concretos relacionados ao ambiente como estando em relação direta e causal com a gestão dos "recursos", elementos e meios naturais, seja com respeito à água, ao ar, às zonas úmidas, às florestas tropicais etc. Essa dimensão, por vezes associada à dimensão econômica, se sobressai a partir de uma dupla constatação: da crescente escassez dos "recursos naturais" básicos, principalmente de "boa qualida$\mathrm{de}^{\prime \prime}$; e, da interdependência total entre os diferentes compartimentos da biosfera, transferindo a poluição de uns para outros (acúmulo na cadeia trófica ou modificação dos equilíbrios do planeta).

Basicamente, são essas dimensões, com suas respectivas interpretações, que fundamentam o ambiente como um todo, como entidade em si. ${ }^{4}$ Em cada um dos aspectos considerados, é somente uma parte ou uma faceta do conjunto formulador do sistema que aparece. O clima, a camada de ozônio, a biodiversidade, por exemplo, assumem um papel unificador, espécie de "globalização" dos fenômenos. Em alguns contex-

\footnotetext{
"Para além do debate entre "realistas" e "construtivistas" na análise da questão ambiental, outros autores (como, por exemplo, Herculano, 2000, Ferreira, 2006 e Bacchiegga, 2013) caracterizam as abordagens teóricas no campo da sociologia ambiental como: a) materialismo durkheimiano; b) materialismo marxista; c) pós-materialismo; d) construtivismo; e) "sociedade de risco"; f) modernização ecológica; e e) "híbridos".
} 
tos, começa-se a falar, cada vez mais, em "mudança global" e menos em "ambiente", submetendo o local a uma verdadeira "ordem planetária", justificando ainda mais a intervenção do "poder público".

A questão do ambiente também inaugura várias outras questões, extremamente diversas em seus conteúdos, apelando para múltiplas disciplinas que pertencem aos grandes setores de pesquisa tradicionais. Isso leva a uma indagação inicial: como conceber um programa de pesquisa ou de interesse nesta área? Saímos de uma fase mais "pragmática" em se tratando da questão, onde a influência monodisciplinar era (e ainda é em alguns casos e contextos) determinante, e entramos em outra, mais complexa e exigente, que é aquela de construção de um conjunto de questões coerentes que fortaleça a prática interdisciplinar.

Mas como pensar a questão do ambiente dentro desta complexidade? Baseado em Jollivet e Pavé (1992; 1993) pode-se organizar a reflexão em torno de seis questões derivadas:

- é necessário - ou se pode - delimitar um campo específico de interesse (para a pesquisa ou para a ação propriamente dita) sobre o ambiente? Em caso afirmativo, que definição deste campo pode servir-lhe de "paradigma"?

- em torno de quais áreas se poderia organizar este campo considerado em seu conjunto?

- quais os problemas teóricos e metodológicos particulares de uma pesquisa (ou ação) sobre o ambiente?

- quais as repercussões das pesquisas ambientais sobre as diferentes disciplinas envolvidas? Como os problemas de ambiente podem orientar, e até mesmo modificar, suas problemáticas, seus processos, seus objetivos? 
- quais fatores devem ser considerados para a escolha de uma estratégia de pesquisa e, consequentemente, qual estratégica adotar? $\mathrm{O}$ que priorizar e por quê?

- que tipos de ações empreender no quadro desta estratégia, levando em conta as características do ambiente enquanto campo de pesquisa e de interesse político para a ação?

A problemática ambiental situa-se na convergência de diversas correntes com preocupações de diferentes origens. Falta, no entanto, uma história global das questões que estão hoje reunidas sob este termo e que formam, juntas, o que se pode chamar de "questão ambiental". De maneira preliminar - como se poderá ver parcialmente nos artigos deste dossiê, talvez ainda de forma um pouco desordenada e certamente incompleta -, propõe-se a seguinte enumeração:

- questão da diversidade biológica, de sua caracterização, dinâmica e papel no suporte e desenvolvimento das sociedades humanas, que remete atualmente ao problema de sua conservação;

- temor de um esgotamento dos "recursos" naturais não renováveis e interrogações sobre as modalidades do desenvolvimento industrial e preocupações relativas à sua "gestão";

- inquietações sobre as utilizações tanto civis como militares da energia nuclear;

- preocupações relativas à evolução da composição da atmosfera (camada de ozônio, efeito estufa, oxidantes etc.), às chuvas ácidas e à evolução do clima;

- problemas de saúde ligados à alimentação, às condições de trabaIho, à água e ao ar;

- problemas de epidemias e saneamento;

- aspirações de melhoria da qualidade de vida e gosto pela natureza; 
- questão da diversidade de culturas humanas e da conservação do patrimônio cultural;

- questão muito recente de ambientes artificiais colocada pela pesquisa espacial;

- os riscos naturais; e,

- o problema da agricultura artificializada, "quimificada".

As pesquisas sociais sobre o ambiente acabam acolhendo em suas problematizações as questões acima, algumas vezes emolduradas por "temas maiores", como sustentabilidade, responsabilidade e inclusão social, decisões em contextos democráticos, a ambivalência da tecnociência para a emergência e soluções dos problemas ambientais, e o equilíbrio nas investigações entre distanciamento e engajamento ou ativismo dos pesquisadores. ${ }^{5}$

Os artigos selecionados para este dossiê, longe de constituírem um estado da arte dos estudos sobre a questão ambiental, representam um pequeno estrato de enfoques e temas relacionados às ciências sociais em que a questão ambiental tem caráter determinante nas análises. Os artigos apresentados visam garantir, como parte dos critérios de seleção, a diversidade teórico-metodológica das pesquisas e abarcar a maior variedade, dentro do possível, de procedências nacionais e internacionais dos autores, com artigos delineando abordagens de vanguarda, com um diapasão que busca intercalar, de forma harmônica, teoria e empírico acerca de questões que tratam dos problemas ambientais vivenciados pelas sociedades contemporâneas.

\footnotetext{
${ }^{5}$ Alonso e Costa (2002) tipificam as abordagens das ciências sociais para a questão ambiental em: a) estudos ambientais e política (movimento ambientalista, ambientalismo global, conflitos ambientais); b) estudos sobre políticas públicas e participação; c) estudos culturais (história das ideias ambientais e percepções sobre o ambiente). Esses autores, ao final do artigo mencionado, relacionam uma vasta bibliografia em ciências sociais sobre a questão ambiental.
} 
O artigo que abre o dossiê, $\mathrm{O}$ ambiente como questão sociológica: conflitos ambientais em perspectiva, de Lorena C. Fleury, Jalcione Almeida e Adriano Premebida, contextualiza a noção de ambiente no âmbito da sociologia e faz uma análise das principais correntes teóricas que se ramificaram em diversas abordagens sobre o tema ambiental. Além de delinear os desdobramentos epistemológicos e teórico-metodológicos que a sociologia ambiental tem com os estudos sociais das ciências e tecnologias, mostra a tendência destacada das análises sobre conflitos ambientais na maior parte das pesquisas latino-americanas.

O segundo artigo, Disputas cognitivas e exercício da capacidade crítica: o caso dos conflitos ambientais no Brasil, de Henri Acselrad, trata justamente da tendência de enfocar as análises ambientais pelo lado das controvérsias e conflitos de diversas ordens e matizes. Da mesma forma, o conhecimento científico é elemento primordial na produção de incertezas, embora um conjunto de informações, dados e especialistas seja arrolado para produzir consensos e acordos através dos resultados das práticas científicas. O problema, tal como analisado pelo autor, é equacionar as temporalidades diferentes da produção científica, de outros saberes e da política. Os atritos causados por esta diferença, com o tema dos impactos ambientais, estabelecem as bases para conflitos muitos mais cerrados, pois na esfera dos debates político-cognitivos, situam os sujeitos epistêmicos e a dinâmica das legitimações das escolhas técnicas por meio das linhas de força do campo científico.

A gestão e avaliação da questão dos riscos (ambientais) e das formas como a noção de incerteza se insere nos processos de decisão de governos é um dos pontos tratados no artigo O surgimento das questões de risco, de Olivier Borraz. Além de analisar o surgimento e uso da noção de risco nas decisões de Estado e das pessoas, como uma forma de abrir um novo leque de ações de governo para a proteção e segurança contra no- 
vas vulnerabilidades, o autor examina, também, que a questão dos riscos é uma estratégia de legitimação de muitas decisões a partir de um instrumento despolitizado, já que baseado pretensamente no conhecimento especializado da ciência.

O estudo de caso de Jean-Paul Billaud, A injunção da participação no campo ambiental ou a questão da incorporação dos "públicos" nos espaços de discussão, discute a deliberação e a participação pública na tomada de decisão de políticas agroambientais na França, em região sensível do ponto de vista ambiental. A pesquisa mostra os limites de modelos de participação pública quando relacionados às questões ambientais, justamente pelo conjunto de considerações e decisões variadas que afloram, pondo em questão, inclusive, as relações tradicionalmente estabelecidas entre conhecimento científico e sociedade.

José Manuel Rodríguez Victoriano e Marina Requena i Mora, com o artigo La reinvención de la autenticidad en el contexto de la mercantilización neoliberal investigam, por meio de rico material empírico, a criação do Parque Natural de la Albufera de Valencia, na Espanha. Através do uso de rigorosas técnicas e métodos de pesquisa qualitativa, com análises de discurso, de imagens e grupos de discussão, apresentam as variadas representações sociais dos usuários, mídia e especialistas ligados à criação e vivência cotidiana no Parque, mostrando o movimento de entrelaçamento de diversos significados que gravitam em um espaço "renaturalizado", mas em meio a domínios cognitivos mais abrangentes, mesmo que divergentes, pois imersos em contextos definidos pela pouca alteração estrutural dos dispositivos de reprodução da economia capitalista.

Os organizadores deste dossiê esperam que o mesmo possa se constituir em instrumento de reflexão e debate para todos aqueles que se dedicam à pesquisa das relações entre sociedade e natureza, e também a todos que pretendem compreender os complexos e intrincados dilemas no campo socioambiental. Boa leitura. 
Jalcione Almeida. Doutor em Sociologia (Université de Paris X), professor associado do Departamento de Sociologia/IFCH-UFRGS, pesquisador permanente nos Programas de Pós-Graduação em Desenvolvimento Rural (PGDR) e Sociologia (PPGS), ambos da Universidade Federal do Rio Grande do Sul (UFRGS), pesquisador $\mathrm{CNPq}$, coordenador do grupo de pesquisa Tecnologia, Meio Ambiente e Sociedade (TEMAS). $\$ jal@ufrgs.br

Adriano Premebida. Doutor em Sociologia (UFRGS), pesquisador e diretor técnico-científico da Fundação de Defesa da Biosfera (FDB), Manaus. Pesquisador associado do grupo de pesquisa Tecnologia, Meio Ambiente e Sociedade (TEMAS). $\triangle$ premebida@hotmail.com

\section{Referências}

1. ALMEIDA, J. O campo de pesquisa e das ações sobre o meio ambiente. Porto Alegre, PGDR/UFRGS, 2000. (Texto para uso didático, não publicado).

2. ALONSO, A; COSTA, V. Ciências sociais e meio ambiente no Brasil: um balanço bibliográfico, BIB, n. 53, p. 35-78, 2002.

3.BACCHIEGGA, F. Desvendando o campo da sociologia ambiental: revisão de artigos selecionados, Sustentabilidade em Debate, Brasília, vol. 4, n. 2, p. 118$137,2013$.

4. BOLTANSKI, L.; THÉVENOT, L. On Justification: Economies of Worth. Princeton: Princeton University Press, 2006.

5. BUTTEL, F. H. Environmental and Resource Sociology: Theoretical Issues and Opportunity for Synthesis, Rural Sociology, n. 61, p. 56-76, 1996.

6. CATTON, W. R. Jr.; DUNLAP, R. E. Enviromental Sociology: a New Paradigm, The American Sociologist, n. 13, p. 41-49, 1978.

7. FERREIRA, L. C. Ideias para uma sociologia da questão ambiental. São Paulo: Annablume, 2006.

8. FERREIRA, L. C.; FERREIRA, L. C. Águas revoltas: um balanço provisório da sociologia ambiental no Brasil, BIB, n. 54, p. 83-100, 2002.

9. FOlTZ, B. V. Habitar a Terra. Heidegger, Ética Ambiental e a Metafísica da Natureza. Lisboa: Instituto Piaget, 1995.

10. HERCULANO, S. Sociologia Ambiental: origens, enfoques metodológicos e objetos, Revista Mundo e Vida: alternativas em estudos ambientais, ano I, n. 1, UFF/PGCA-Riocor, p. 45-55, 2000. 
11. JOLLIVET, M.; PAVÉ, A. L'environnement: questions et perspectives pour la recherche, Lettres des Programmes Interdisciplinaires de Recherche du CNRS, CNRS, n. 6, mai. 1992.

12. JOLLIVET, M.; PAVÉ, A. L'environnement: un champ de recherche en formation, Natures, Sciences, Sociétés, vol. 1, n. 1, p. 6-24, 1993.

13. VIVEIROS DE CASTRO, E. B. A Inconstância da alma selvagem e outros ensaios de antropologia. São Paulo: Cosac \& Naify, 2002. 